\title{
UM ESTADO DO CONHECIMENTO EM RELAÇÃO A FORMAÇÃO CONTINUADA PARA PROFESSORES QUE ENSINAM MATEMÁTICA NOS ANOS INICIAIS DO ENSINO FUNDAMENTAL NA AMAZÔNIA LEGAL BRASILEIRA ${ }^{1}$
}

\author{
A STATE OF KNOWLEDGE REGARDING CONTINUING EDUCATION FOR \\ TEACHERS WHO TEACH MATHEMATICS IN THE EARLY YEARS OF \\ ELEMENTARY SCHOOL IN THE BRAZILIAN LEGAL AMAZON
}

Idemar Vizolli ${ }^{2}$

ORCID iD: 0000-0002-7341-7099

Pedro Franco de $\mathrm{Sá}^{3}$

ORCID iD: 0000-0002-8986-2787

\begin{abstract}
RESUMO
Este artigo resulta de uma pesquisa vinculada ao PROCAD - AMAZÔNIA, o qual desenvolve ações integradas para qualificar a formação na pós-graduação em educação no Pará, Tocantins e Rio Grande do Norte; e ao projeto mais amplo do Programa de Doutorado da Rede Amazônica de Ensino de Ciências e Matemática - REAMEC, que está desenvolvendo um estudo com o objetivo de mapear as pesquisas que tematizam a formação de professores na Amazônia Legal Brasileira (ALB). Este estudo tem como objetivo construir um panorama com os enfoques das pesquisas que tematizam a formação continuada para professores que ensinam Matemática nos Anos Iniciais do Ensino Fundamental, produzidas em Instituições de Ensino Superior localizadas na ALB. Trata-se de um estudo bibliográfico, de abordagem qualitativa, no escopo do estado do conhecimento, cujas produções encontram-se no repositório do Catálogo de Teses e Dissertações da Capes. Foram encontradas 955 teses e 2312 dissertações, defendidas entre os anos de 2015 a 2019. Ao refinar a busca a partir dos títulos, palavras-chave e resumo, foram selecionadas 01 (uma) tese e 07 (sete) dissertações. Ao proceder as análises verificou-se a predominância de 05 (cinco) palavras-chave, com prevalência em formação continuada; que as pesquisas têm assento nos processos de ensino e aprendizagem de matemática no ciclo de alfabetização e/ou objetos matemáticos específicos e na avaliação de Programas e Planos de Formação continuada desenvolvidos na ALB. Os resultados reverberam a necessidade de políticas de formação continuada permanentemente, de modo a atender as demandas da formação humanizada, localizada e que contemple a riqueza sociocultural da ALB.
\end{abstract}

Palavras-chave: Educação. Formação continuada. Ensino e aprendizagem de Matemática. Anos Iniciais do Ensino Fundamental.

\begin{abstract}
This article results from a research linked to PROCAD - AMAZON, which develops integrated actions to qualify graduate education training in Pará, Tocantins and Rio Grande do Norte; and the broader project of the Doctoral Program of the Amazon Network of Science and Mathematics Teaching -

\footnotetext{
${ }^{1}$ Esta pesquisa contou com financiamento pelo CNPq.

${ }^{2}$ Doutor em Educação pela UFPR. Professor na UFT. Palmas, TO. Endereço: Qd 108N, Al 16, Lt 08, Residencial Solar dos Mognos, Apto 306, Palmas, TO.CEP 77006-118 E-mail: idemar@uft.edu.br.

3 Doutor em Educação pela UFRN. Professor Titular da UEPA, Belém, PA. Endereço: Av Senador Lemos 4307, Sacramenta, Belém, PA. E-mail pedro.franco.sa@gmail.com.
} 
REAMEC, which is developing a study with the objective of mapping the research that theme the training of teachers in the Brazilian Legal Amazon (ALB). This study aims to build an overview with the research approaches that theme continuing education for teachers who teach Mathematics in the Early Years of Elementary School, produced in Higher Education Institutions located in the ALB. This is a bibliographic study, with a qualitative approach, in the scope of the state of knowledge, whose productions are found in the repository of the Capes Catalogue of Theses and Dissertations. We found 955 theses and 2312 dissertations, defended between 2015 and 2019. When refining the search from the titles, keywords and abstract, 01 (one) thesis and 07 (seven) dissertations were selected. When carrying out the analyses, there was a predominance of 05 (five) keywords, with prevalence in continuing education; that research sits on the teaching and learning processes of mathematics in the literacy cycle and/or specific mathematical objects and in the evaluation of Programs and Continuing Training Plans developed at ALB. The results reverberate the need for policies of continuous formation permanently, in order to meet the demands of humanized, localized training that contemplates the sociocultural richness of ALB.

Keywords: Education. Continuing education. Mathematics teaching and learning. Early Years of Elementary School.

\section{O sobrevoo pela Amazônia ${ }^{4}$}

Ao sobrevoar pela Amazônia situamos o lugar de onde se está falando e delimitamos o objeto de estudo. Nos últimos tempos pesquisadores têm se dedicado ao estudo de situações enfrentadas por grupos sociais que resistem às imposições da sociedade hegemônica, como por exemplo, sem terras, indígenas, quilombolas, quebradeiras de coco, atingidos por barragens, dentre outros. Ademais, a Base Nacional Comum Curricular (BNCC) preconiza um olhar mais acurado em relação a diversidade cultural brasileira, o que nos imputa a reponsabilidade de conhecermos e vivenciarmos situações de ensino e aprendizagens que abarquem essa riqueza de diversidade antropológica e sociocultural.

Nessa perspectiva, o PROCAD - AMAZÔNIA, desenvolve ações integradas para qualificar a formação na pós-graduação em educação no Pará, Tocantins e Rio Grande do Norte, no qual se insere este estudo de pós-doutoramento. A presente pesquisa vincula-se também ao projeto mais amplo do Programa de Doutorado da Rede Amazônica de Ensino de Ciências e Matemática - REAMEC, que está desenvolvendo um estudo com o objetivo de mapear e construir um panorama das pesquisas que tematizam a formação de professores na Amazônia Legal Brasileira.

\footnotetext{
4 As metáforas que intitulam as seções, fazem alusão a diversidade da riqueza socioambiental e cultural da Amazônia Legal Brasileira.
} 
Neste estudo nos desafiamos a desenvolver uma investigação com vistas a responder a seguinte pergunta de pesquisa: o que revelam as pesquisas sobre formação continuada de Matemática para professores de Anos Inicias do Ensino Fundamental produzidas em Instituições de Ensino Superior localizadas na Amazônia Legal Brasileira?

Assim, estabelecemos como objetivo geral desta pesquisa: construir um panorama com os enfoques das pesquisas que tematizam a formação continuada para professores que ensinam Matemática nos Anos Iniciais do Ensino Fundamental, produzidas em Instituições de Ensino Superior localizadas na Amazônia Legal Brasileira.

Para tanto, estabelecemos como objetivos específicos:

a) Identificar enfoques de dissertações e teses elaboradas em Programas de Instituições de Ensino Superior localizadas na Amazônia Legal Brasileira que tematizam a formação continuada em Matemática para professores de Anos Iniciais do Ensino Fundamental;

b) Identificar os pressupostos teóricos e metodológicos que sustentam as pesquisas que tematizam a formação continuada em Matemática, para professores de Anos Iniciais do Ensino Fundamental, desenvolvidas em Instituições de Ensino Superior localizadas na Amazônia Legal Brasileira;

c) Desvelar contribuições que as pesquisas que tematizam a formação continuada em Matemática para professores de Anos Iniciais do Ensino Fundamental, desenvolvidas em Instituições de Ensino Superior localizadas na Amazônia Legal Brasileira, trazem à formação docente e aos Programas e Planos de Formação Docente;

d) Indicar limitações e lacunas existentes na formação continuada de professores, no intuito de apresentar demandas e necessidades aos Programas e Planos de Formação Docente.

O sobrevoo permitiu olhar alguns elementos paisagem que compõe a Amazônia Legal Brasileira, mas é preciso aterrissar, para ver o que mais existe desses elementos e de seus reflexos nas e entre as terras, águas e florestas.

Este estudo está organizado em quatro etapas: o sobrevoo pela Amazônia, em que se fez a escolha e delimitação do objeto de investigação; a jornada pelas águas amazônicas, na qual se apresenta o levantamento e seleção do material de estudo; o mergulho nas águas, onde se apresenta as 8 (oito) produções encontradas; e a caminhada em terra firme que se constitui na análise dos "achados" nas e das produções. 


\title{
2. Uma jornada pelas águas amazônicas
}

A jornada pelas águas amazônicas tem o intento de demarcar o campo metodológico do estudo, o qual tem assento na pesquisa bibliográfica, de abordagem qualitativa, com escopo do estado do conhecimento.

De acordo com Gil (2002), Marconi; Lakatos (2003), a pesquisa bibliográfica se constitui a partir de material já publicizado, como é o caso das teses e dissertações, que são produções científicas, que ao se estabelecer relação entre os objetos de estudo e examinadas em consonâncias umas às outras, possibilitam a proposição de novas investigações, e ainda podem indicar imbricagens importantes para a compreensão do cenário pesquisado. Para Santos (2007), ela abarca uma gama de fenômenos com ideias já constituídas, cuja consulta é fundamental às pesquisas.

\begin{abstract}
A principal vantagem da pesquisa bibliográfica reside no fato de permitir ao investigador a cobertura de uma gama de fenômenos muito mais ampla do que aquela que poderia pesquisar diretamente. (...) convém aos pesquisadores assegurarem-se das condições em que os dados foram obtidos, analisar em profundidade cada informação para descobrir possíveis incoerências ou contradições e utilizar fontes diversas, cotejando-as cuidadosamente (GIL, 2002, p. 45).
\end{abstract}

As pesquisas qualitativas denotam preocupação em compreender pormenorizadamente as situações observadas, de modo a alcançar a complexidade do fenômeno. Neste sentido, acredita-se que os fatos e fenômenos da realidade estão envoltos em complexidades que lhes são próprias e que múltiplos fatores interferem no objeto de estudo e devem ser levados em conta no desenvolvimento, análises e conclusões da pesquisa. Assim, se faz necessário que o pesquisador capte o fenômeno de estudo a partir da perspectiva de entender a dinâmica de como este se apresenta, o que é válido inclusive às pesquisas bibliográficas com foco no estado da arte ou do conhecimento.

Na perspectiva dos estudos qualitativos,

um fenômeno pode ser melhor compreendido no contexto em que ocorre e do qual é parte, devendo ser analisado numa perspectiva integrada. (...), enquanto exercício de pesquisa, não se apresenta como uma proposta rigidamente estruturada, ela permite que a imaginação e a criatividade levemos investigadores a propor trabalhos que explorem novos enfoques. (GODOY, 1995, p. 21).

De acordo com Ferreira (2002), encontramos muitas pesquisas desenvolvidas a partir do "estado da arte" ou "estado do conhecimento", as quais caracterizam-se como estudos bibliográficos e comumente se dispõem a analisar a produção acadêmica, na perspectiva de 
abarcar aspectos privilegiados (ou não), mas que são importantes do ponto de vista da elaboração de novos conhecimentos.

Também são reconhecidas por realizarem uma metodologia de caráter inventariante e descritivo da produção acadêmica e científica sobre o tema que busca investigar, à luz de categorias e facetas que se caracterizam enquanto tais em cada trabalho e no conjunto deles, sob os quais o fenômeno passa a ser analisado (FERREIRA, 2002, p. 258).

Uma vez que o presente estudo se propõe em fazer uma ausculta em teses e dissertações que tematizam a formação continuada em Matemática para professores de Anos Inicias, depositadas na Plataforma Sucupira e defendidas no período de 2015-2019, entendemos que se configura como uma pesquisa com escopo no estado do conhecimento.

Estado do conhecimento é identificação, registro, categorização que levem à reflexão e síntese sobre a produção científica de uma determinada área, em um determinado espaço de tempo, congregando periódicos, teses, dissertações e livros sobre uma temática específica (MOROSINI, 2015, p. 102).

No percurso pelas águas realizou-se o levantamento das publicações disponíveis na Plataforma Sucupira (https://sucupira.capes.gov.br/sucupira/), presentes no repositório do Catálogo de Teses e Dissertações da Capes (http://catalogodeteses.capes.gov.br/catalogoteses/\#!/), a partir do conjunto de palavras e caracteres "Saberes Docentes" + "Formação Continuada" + "Matemática" + "Anos Iniciais" + "Amazônia Legal Brasileira". Foram encontradas 955 teses e 2312 dissertações, totalizando 3267 produções $^{5}$. Sob o entendimento de que estas pesquisas contemplam o escopo do presente estudo, consideramos as produções dos últimos 05 (cinco) anos (2015 a 2019), indexadas nas áreas de conhecimento (Educação, Ensino de Ciências e Matemática e Matemática) e de concentração (Educação, Ensino de Ciências e Matemática, Educação Matemática e Matemática), cujos dados foram sistematizados nos Quadros 01 a 04.

\begin{tabular}{|c|c|}
\hline Teses & 955 \\
\hline Dissertações & 2312 \\
\hline
\end{tabular}

Quadro 01 - Quantitativo de produções indicadas

Fonte: Elaborada pelos pesquisadores.

\begin{tabular}{|c|c|c|c|c|c|}
\hline Anos & $\mathbf{2 0 1 5}$ & $\mathbf{2 0 1 6}$ & $\mathbf{2 0 1 7}$ & $\mathbf{2 0 1 8}$ & $\mathbf{2 0 1 9}$ \\
\hline Quantidade & 846 & 881 & 930 & 411 & 199 \\
\hline
\end{tabular}
Fonte: Elaborada pelos pesquisadores.

\footnotetext{
${ }^{5}$ A busca do material na internet ocorreu no dia 23 de janeiro de 2020.
} 


\begin{tabular}{|c|c|c|c|}
\hline Área conhecimento & Educação & Ensino de Ciências e Matemática & Matemática \\
\hline Quantidade & 1749 & 1176 & 342 \\
\hline
\end{tabular}

Quadro 03 - Quantitativo de produção por área de conhecimento

Fonte: Elaborada pelos pesquisadores.

\begin{tabular}{|c|c|c|c|c|}
\hline $\begin{array}{c}\text { Área } \\
\text { concentração }\end{array}$ & Educação & $\begin{array}{c}\text { Ensino de Ciências e } \\
\text { Matemática }\end{array}$ & $\begin{array}{c}\text { Educação } \\
\text { Matemática }\end{array}$ & Matemática \\
\hline Quantidade & 1749 & 659 & 517 & 342 \\
\hline \multicolumn{5}{|c}{ Quadro 04 - Quantitativo de produção por área de concentração } \\
\hline \multicolumn{4}{|c}{ Fonte: Elaborada pelos pesquisadores. }
\end{tabular}

Ao analisar os dados verifica-se um quantitativo significativo de produção que merece ser estudado de forma mais acurada, haja vista que grande parte das teses e dissertações foram defendidas no período de 2015 a 2018, com maior incidência nas áreas da Educação, Ensino de Ciências e Matemática e Educação Matemática. Certamente a alta produção acadêmica nesse período tem relação com a implantação do Plano de Ações Articuladas (PAR), com implicações diretas à formação continuada para professores do ciclo de alfabetização via Pacto Nacional pela Alfabetização na Idade Certa (PNAIC).

Na continuidade do refinamento, fizemos uma leitura dos títulos, a fim de verificar se a produção se enquadrava no escopo do estudo, apresentando, mesmo que parcialmente, as palavras-chave de busca, (saberes docentes; formação continuada; Matemática; Anos Inicias; Amazônia Legal Brasileira), ao que foram destacadas 218 produções, das quais foram selecionadas 13 Dissertações e 06 Teses (uma delas não conta com autorização para divulgação). As demais (199), necessitaram de um novo refinamento (leitura dos resumos e/ou palavras-chave), de modo a encontrar aquelas que contemplam os termos de busca (Formação continuada; Matemática; Anos Inicias) em que foram encontradas 15 teses e 42 dissertações, destas foram destacadas 07 (sete) Dissertações e 01 (uma) Tese. Registra-se, no entanto, que em nenhuma das produções constam todos os termos de busca e em nenhuma delas encontramos a palavra de busca Amazônia Legal Brasileira (ALB), fato este que nos conduziu a analisar as produções realizadas nos Programas de Mestrado e Doutorado ofertados em Instituições localizadas nos estados do Acre, Amazonas, Amapá, Pará, Rondônia, Roraima, Tocantins (Norte), Mato Grosso (Centro Oeste) e Maranhão (Nordeste).

A jornada pelos rios e estradas amazônicas nos conduziu à navegação a fim de selecionar as riquezas a serem estudadas. 


\section{Um mergulho nas águas amazônicas}

Ao navegar pelas águas amazônicas nos desafiamos a um mergulho a fim de apresentar informações relativas às 07 (sete) Dissertações e 01 (uma) Tese das quais buscamos as palavraschave indicadas pelos respectivos autores, conforme disposto no Quadro 05.

Ao mergulhar nas águas dos rios amazônicos voltamos nosso olhar em relação aos enfoques e principais autores que fundamentam as pesquisas que tematizam a formação continuada em Matemática, para professores de Anos Iniciais do Ensino Fundamental, produzidas em Instituições de Ensino Superior localizadas na Amazônia Legal Brasileira.

\begin{tabular}{|c|c|}
\hline Temáticas & Objetivos \\
\hline $\begin{array}{l}\text { Tese } \\
\text { Vivências autoformativas no ensino } \\
\text { de Matemática: vida e formação em } \\
\text { escolas ribeirinhas. } \\
\text { Autora: Lucélida de Fátima Maia da } \\
\text { Costa } \\
\text { Instituição/ANO: UFPA/2015 } \\
\text { Palavras-chave: } \\
\text { - Formação de professores } \\
\text { - Autoformação } \\
\text { - Complexidade } \\
\text { - Transdisciplinaridade }\end{array}$ & $\begin{array}{l}\text { Geral } \\
\text { Analisar como práticas formativas, mobilizadas em processos } \\
\text { de formação continuada de professores que ensinam } \\
\text { matemática, podem viabilizar um ensino que considere, além } \\
\text { da ciência, o contexto, a experiência, o conhecimento } \\
\text { produzido e as formas vigentes de ensinar e aprender em } \\
\text { comunidades ribeirinhas como elementos inerentes à formação } \\
\text { de um sujeito local e global simultaneamente. } \\
\text { Questionamentos } \\
\text { 1) Que elementos constituem o ideário pedagógico de } \\
\text { professores que ensinam matemática em escolas de } \\
\text { comunidades ribeirinhas? } \\
\text { 2) Como aparece a matemática na fala dos professores? } \\
\text { 3) Como aspectos decorrentes das experiências de vida podem } \\
\text { influenciar na ação docente do professor que ensina matemática } \\
\text { em escolas ribeirinhas e do professor formador? } \\
\text { 4) Como as experiências de vida podem ser mobilizadas no } \\
\text { processo de constituição docente, durante uma formação } \\
\text { continuada, de modo a influenciar possíveis ações didáticas } \\
\text { para o ensino de matemática desenvolvido por professores de } \\
\text { escolas ribeirinhas e por professores formadores nessa } \\
\text { realidade? }\end{array}$ \\
\hline $\begin{array}{l}\text { Dissertação } \\
\text { Saberes docentes na/da formação } \\
\text { continuada de professores que } \\
\text { ensinam Matemática no ciclo de } \\
\text { alfabetização } \\
\text { Autor: Fabio Colins da Silva } \\
\text { Instituição/ANO: UFPA/2015 } \\
\text { Palavras-chave: } \\
\text { - Saberes Docentes } \\
\text { - Formação Continuada } \\
\text { - Alfabetização Matemática }\end{array}$ & $\begin{array}{l}\text { Geral } \\
\text { Investigar em que termos os saberes docentes são mobilizados } \\
\text { a partir da formação continuada de professores alfabetizadores }\end{array}$ \\
\hline $\begin{array}{l}\text { Dissertação } \\
\text { Estudo e ensino de frações: } \\
\text { aprendizagens e dificuldades docentes } \\
\text { no processo de formação continuada }\end{array}$ & $\begin{array}{l}\text { Pergunta de pesquisa } \\
\text { Quais as dificuldades e as aprendizagens de professores do } 4^{\circ} \\
\text { e } 5^{\circ} \text { ano do Ensino Fundamental, manifestadas durante o }\end{array}$ \\
\hline
\end{tabular}


Autora: Vani Terezinha Siebert Silva

Instituição/ANO: UFMT/2015

- Frações

- Formação Continuada

- Aprendizagens

- Dificuldades

- Atividade
Palavras-chave

processo formativo, em relação ao conhecimento específico, pedagógico e curricular sobre frações?

\section{Objetivos Específicos}

* Caracterizar e analisar a relação acadêmica e profissional de professores com a matemática e com as frações;

* Identificar e analisar os dilemas, conflitos e dificuldades dos professores quanto à compreensão e ao ensino de frações;

* Identificar e analisar as aprendizagens docentes em relação ao conhecimento específico, curricular e pedagógico do conteúdo de frações;

* Analisar em situação de ensino, as aprendizagens e dificuldades manifestadas pelas professoras.

\section{Dissertação}

Pacto Nacional pela Alfabetização na Idade Certa (PNAIC): as vozes de professoras sobre a formação Matemática

Autora: Ieda Maria Valle Monteiro Callejas

\section{Instituição/ANO: UFMT/2017}

\section{Palavras-chave}

- PNAIC Matemática

- Formação Continuada

- Relato de Professoras

\section{Geral}

Analisar, a partir das vozes das professoras participantes, como e ao desenvolvimento dos processos de aprender e ensinar Matemática nos anos iniciais.

\section{Específicos}

- Identificar uma escola em que todas as professoras do primeiro ciclo tivessem participado da formação do Pacto Nacional pela Alfabetização na Idade Certa Matemática;

- Caracterizar o percurso acadêmico-profissional das professoras participantes da pesquisa;

- Investigar o que dizem as professoras sobre as aprendizagens e dilemas vivenciados na formação do PNAIC- Matemática; continuada e as práticas escolares em compreendem a formação do PNAIC, bem como à organização

- Analisar o que relatam as professoras sobre como compreendem a aprendizagem e desenvolvem o ensino da matemática com as crianças do primeiro ciclo.

\section{Dissertação}

A solução de situações que envolvem o conceito de fração por professores que ensinam Matemática nos anos iniciais

Autor: Marcos José Pereira Barros

\section{Instituição/ANO: UFT/2018}

\section{Palavras-chave}

- Educação

- Educação Matemática

- Ensino e Aprendizagem de Fração

- Registros de Representação Semiótica

- Significados de Fração

- Características das quantidades

- Professores de Anos Iniciais

\section{Geral}

Verificar o modo como professores que ensinam matemática nos Anos Iniciais do Ensino Fundamental de Araguaína, TO, resolvem situações que envolvem o conceito de fração, considerando o uso de registros de representação semiótica, os diferentes significados de fração, bem como as características das quantidades.

Específicos

- Averiguar se os professores de $4^{\circ}$ e $5^{\circ}$ Ano do Ensino Fundamental conhecem diferentes significados de fração e as reconhecem em diferentes registros de representação semiótica;

- Identificar, por meio de uma sequência de atividades, conhecimentos matemáticos que os professores de $4^{\circ}$ e $5^{\circ}$ Ano do Ensino Fundamental mobilizam para resolver situações que envolvem fração;

- Examinar o modo como professores de $4^{\circ}$ e $5^{\circ}$ Ano do Ensino Fundamental, que atuam na Rede Municipal de Ensino de Araguaína, TO, resolvem situações que envolvem fração, a partir de uma sequência de atividades, considerando significados de fração, o uso de diferentes registros de representação semiótica e a natureza das quantidades.

\section{Geral}

Formação continuada de professores que ensinam Matemática no primeiro ciclo: análise do projeto de estudos e
Analisar como os professores compreenderam, desenvolveram e avaliaram as ações que envolveram os conhecimentos matemáticos no PEIP.

Específicos 
intervenções pedagógicas em uma escola pública de Cáceres, MT.

Autora: Lenir Tomazeli

Instituição/ANO: UFMT/2018

\section{Palavras-chave}

- Formação Continuada

- Educação Matemática

- Ensino-aprendizagem

Dissertação

O programa ALFAMAT na prática pedagógica de professores: um estudo em escolas municipais vinculadas à SEMEC - Belém.

Autora: Nila Luciana Vilhena Madureira

Instituição/ANO: UFPA/2019

Palavras-chave

- Formação Continuada de Professores

- ALFAMAT

- Prática Pedagógica

\section{Dissertação}

Entre números e letras considerações de professoras alfabetizadoras da escola de tempo integral Padre Josimo Morais Tavares (Palmas-TO), sobre as contribuições do PNAIC para suas práticas de ensino de Matemática

Autora: Seila Alves Pugas

Instituição/ANO: UFT/2018

\section{Palavras-chave}

- Letramento matemático

- PNAIC

- Ciclo de Alfabetização

- Formação continuada

- Alfabetizadoras
- Identificar a percepção das professoras sobre os estudos teóricos realizados;

- Compreender quais foram as relações estabelecidas pelas professoras entre as avaliações internas, externas e as ações do PEIP;

- Identificar como as professoras relacionaram os estudos e projetos realizados no PEIP com suas necessidades formativas e dos alunos;

- Identificar quais foram os dilemas, os conflitos e as aprendizagens manifestadas pelos professores na participação da formação continuada PEIP.

\section{Geral}

Fazer uma análise sobre o Programa ALFAMAT (Programa de Formação Continuada de Professores Alfabetização Matemática, Leitura e Escrita), ofertado pela SEMEC/Belém (Secretaria Municipal de Educação e Cultura), no sentido de saber quais são as percepções dos professores atuantes no Ciclo II do Ensino Fundamental das Escolas do Município de Belém, sobre o referido programa.

\section{Específicos}

- Caracterizar o Programa ALFAMAT no que se refere aos seus fundamentos teóricos e metodológicos voltados para a prática pedagógica dos professores do Ciclo II;

- Analisar o processo de implementação do programa ALFAMAT com os professores das turmas de Ciclo II das Escolas Municipais;

- Investigar a percepção dos professores do CII no que se refere ao ALFAMAT.

\section{Geral}

Verificar contribuições do PNAIC ao processo de ensino de matemática no Ciclo de Alfabetização, na Escola de Tempo Integral Padre Josimo Morais Tavares, em Palmas, TO

Específicos

- Identificar nos cadernos do PNAIC o enfoque dado ao ensino de matemática, considerando os aspectos metodológicos e a avaliação das aprendizagens;

- Explicitar como acontece o planejamento das aulas para o ensino de matemática no Ciclo de Alfabetização na ETI Padre Josimo de Tavares Morais, em Palmas, TO;

- Identificar contribuições do PNAIC ao processo de ensino de Matemática no Ciclo de Alfabetização, junto às professoras alfabetizadoras, supervisores pedagógicos da Unidade de Ensino (UE) e coordenadora do PNAIC.

Quadro 05 - Dissertações e teses defendias em IES da ALB (2015-2019)

Fonte: Elaborado pelos pesquisadores.

Pelo que consta no quadro 05, percebe-se que as produções das teses e dissertações (objeto de análise) se concentram em três instituições e são oriundas de programas das áreas de Educação, Ensino de Ciências e Matemática. Na Universidade Federal do Pará (UFPA) foram produzidas uma tese e duas dissertações; na Universidade Federal do Mato Grosso (UFMT) 
foram desenvolvidas três dissertações; e na Universidade Federal do Tocantins, foram defendidas duas dissertações de mestrado. A UFPA e UFMT são instituições consolidadas e com muita produção de pesquisa nas mais diferentes áreas do conhecimento e reconhecidas por sua inserção social, sobretudo na Amazônia Legal Brasileira. Já a UFT teve sua implantação em 2003, portanto, após a criação do estado do Tocantins e mesmo contando com sete campi distribuídos pelo estado, figura entre as IES em fase de consolidação. Registra-se, no entanto, que os programas de pós-graduação são os principais responsáveis pela produção científica nas diferentes áreas do conhecimento.

Para analisar a evocação de palavras-chave constantes no quadro 05 , construímos o Gráfico 01.

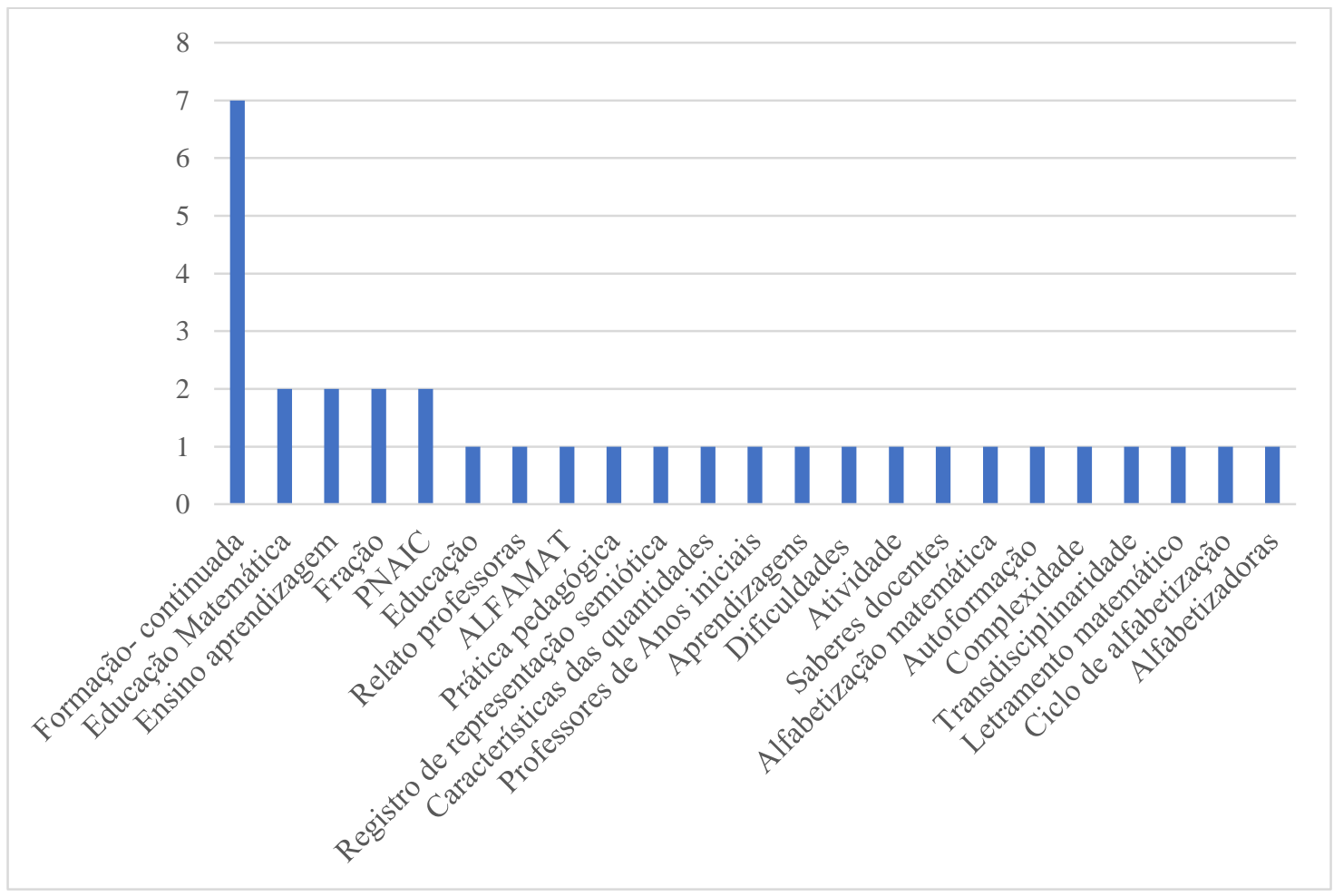

Gráfico 01 - Frequência simples com a evocação de palavras-chave Fonte: Elaborado pelos pesquisadores.

Nos quantitativos indicados no gráfico constam a evocação de 33 palavras-chave, das quais formação continuada teve a maior frequência (07 evocações), seguida por educação matemática, ensino-aprendizagem, fração e PNAIC, com duas evocações cada uma. Um olhar mais atento, é possível inferir que algumas das demais palavras-chave podem ter o mesmo sentido entre si ou mesmo com as que foram mais evocadas, embora possam ter significados diferentes. Podem ainda figurar categorias indicativas de enfoques das pesquisas. 
Educação matemática, ensino de matemática, alfabetização matemática, letramento matemático configura uma categoria de pesquisa que se dedica aos processos de ensino e aprendizagem de matemática no Ciclo de Alfabetização ( $1^{\circ}$ ao $3^{\circ}$ ano do Ensino Fundamental) ou mesmo nos Anos Inicias do Ensino Fundamental ( $1^{\circ}$ ao $5^{\circ}$ anos); fração e significados de fração indica estudos voltados aos processos de ensino e aprendizagem de objetos matemáticos específicos; ciclo de alfabetização, anos iniciais, escolas ribeirinhas configura o escopo de escolas multisseriadas e/ou de escolas que atendem estudantes do $1^{\circ}$ ao $5^{\circ}$ anos do Ensino Fundamental; saberes docentes, práticas pedagógicas figuram no processo de desenvolvimento profissional, coadunando-se com formação continuada, auto formação, estas últimas voltadas aos atendimentos amplos e específicos da formação e desenvolvimento profissional; atividade; complexidade, transversalidade suscitam estudos focados nos processos de humanização.

Interessante observar também que a maioria das pesquisas selecionadas derivam de cursos de formação continuada desenvolvidos a partir de políticas públicas e de âmbito nacional, a exemplo do Pacto Nacional pela Alfabetização da Idade Certa (PNAIC), como é o caso de (SILVA, 2015; CALLEJAS, 2017; PUGAS, 2018); de abrangência estadual, como o Projeto de Estudos e Intervenções Pedagógicas (PEIP), desenvolvido no estado do MT (TOMAZELI, 2018); desenvolvido por redes municipais como o Programa de Formação Continuada de Professores Alfabetização Matemática, Leitura e Escrita (ALFAMAT), ofertado pela Secretaria Municipal de Educação e Cultura de Belém, PA (MADUREIRA, 2019); ou ainda, projetos desenvolvidos por grupos de estudos ou pesquisas, como é o caso do Projeto Observatório da Educação com foco em Matemática e iniciação às Ciências (OBEDUC), em que desenvolveu a pesquisa Siebert Silva (2015) e Aprendendo Matemática (BARROS, 2018).

Metodologicamente caracterizam-se como pesquisas qualitativas (GODOY, 1995) em que se desenvolveram estudos empíricos na área da educação ou do ensino de matemática, especialmente com docentes e/ou outros profissionais da educação que atuam nos espaços escolares.

Ao sobrevoar a floresta amazônica, navegar e mergulhar nas profundezas de suas águas, tivemos a oportunidade de conhecer a 'balbúrdia' da riqueza intelectual imensurável, que deve ser estudada a fim de ser preservada e, ao mesmo tempo, servir de inspiração para o desenvolvimento de novas pesquisas, inclusive com um olhar mais atento às narrativas de professores alfabetizadores (VIZOLLI; PUGAS, 2020). Para tanto, se faz mister um andarilhar sobre o solo firme, a fim de identificar mistérios entranhados na floresta e encrustados na terra em que pisamos e assim, analisar as informações, a partir do ponto de vista dos autores das teses e dissertações estudadas. 


\section{A caminhada em terra firme}

A caminhada em terra firme nos conduz a auscultar o que as dissertações e a tese estudadas indicam como possiblidades às novas jornadas e desafios a serem enfrentados por aqueles que se dedicam ao processo de formação de professores, sobretudo na Amazônia Legal Brasileira. Perpassamos pelas pesquisas que tematizam os saberes docentes (COSTA, 2015; SILVA, 2015); processos de ensino e aprendizagem de matemática (CALLEJAS, 2017; PUGAS, 2018; TOMAZELI, 2018; MADUREIRA, 2019); e processos de ensino e aprendizagem de fração (SIEBERT SILVA, 2015; BARROS, 2018).

Costa (2015) analisou como as práticas formativas de 08 (oito) professores que ensinam Matemática nos Anos Iniciais em escolas ribeirinhas nos estados do Amazonas e Pará, viabilizam práticas educativas inerentes à formação de um sujeito local e global simultaneamente. A partir das ideias e teorias de transdisciplinaridade de que tratam Morin, Galvani, Josso e Nóvoa e de Educação Matemática de que nos fala D’Ambrosio, Costa (2015, p. 4) concluiu,

que quando a formação continuada se realiza de modo reflexivo e dialógico, situado no contexto aonde a ação docente acontece, alarga as possibilidades de fortalecimento de relações com o saber matemático viabilizando sua corporificação em ações didáticas, possibilita o desenvolvimento de práticas transdisciplinares e proporciona uma autoformação ao professor formador.

Para analisar os saberes docentes mobilizados por cinco professoras alfabetizadores que participaram da formação continuada pelo Pacto Nacional pela Alfabetização na Idade Certa (PNAIC) em 2014, no município de Marabá, PA, Silva (2015) analisou produções e narrativas didáticas escritas e videografadas pelas participantes da equipe da pesquisa. Diante disso, sustentou sua pesquisa nos estudos sobre saberes docentes de Shulman, Gauthier e Tardif; em relação a formação e desenvolvimento profissional de professores baseou-se em Imbernón; e em relação a alfabetização matemática tomou como base os estudos de Fonseca. Silva (2015) conclui sua pesquisa dizendo

que a partir da formação continuada e da ação educativa cotidiana os docentes mobilizam uma pluralidade de saberes: saberes da experiência, saberes do conteúdo, saberes pedagógicos, saberes curriculares e saberes da ciência da educação, os quais são necessários à prática de alfabetização matemática (SILVA, p. 2015, p.7).

Por meio de narrativas de três professoras de Cuiabá, (MT), Callejas (2017) analisou a compreensão que as participantes de sua pesquisa têm sobre o PNAIC, assim como em relação a organização e desenvolvimento dos processos de ensinar e aprender matemática nos Anos 
Iniciais do Ensino Fundamental. Sua pesquisa ancora-se nos estudos referentes a Matemática na infância (D’Ambrosio; Nacarato, Mengali, Passos; Moura; Palma); em relação a formação continuada dialoga com Nóvoa, Garcia, Imbernón, Tardif e Gatti. Callejas (2017) concluiu sua pesquisa dizendo que

as professoras apontam aspectos positivos no tocante às contribuições da formação, a partir de elementos comuns, como: a organização dos direitos de aprendizagem, a organização das aulas a partir da sequência didática e a contribuição dos jogos no processo de ensino e aprendizagem. Os destaques dos relatos foram para os jogos e a sequência didática, e ambos carecerem de mais estudos e reflexões para sua consolidação na prática pedagógica das professoras. As mesmas tecem críticas quanto ao desenvolvimento da formação, o pouco tempo destinado à realização das atividades programadas e a articulação com os gestores escolares, bem como a demora de acesso aos cadernos de atividades. A partir disso, concluímos que, para que um programa de formação continuada se efetive é necessário partir das necessidades apresentadas pelos próprios professores. Além disso, o coordenador pedagógico deve assumir papel central de articulador das ações formativas de modo a promover o desenvolvimento da equipe pedagógica como um todo. (CALLEJAS, 2017, p. 6).

Callejas (2017) reporta-se ao uso de Sequência Didática (SD) a partir do material disponibilizado pelo PNAIC. A concepção de SD nesse material tem assento em Zabala (1998, p. 18), o qual a concebe como "um conjunto de atividades ordenadas, estruturadas e articuladas para a realização de certos objetivos educacionais, que têm um princípio e um fim conhecidos tanto pelo professor como pelos alunos". Para Oliveira (2013, p, 39), a "sequência didática é um procedimento simples que compreende um conjunto de atividades conectadas entre si, e prescinde de um planejamento para delimitação de cada etapa e/ou atividade para trabalhar os conteúdos disciplinares de forma integrada para uma melhor dinâmica no processo ensino aprendizagem". Ainda,

A sequência didática é um procedimento para a sistematização do processo ensinoaprendizagem, sendo de fundamental importância a efetiva participação dos alunos. Essa participação vai desde o planejamento inicial informando aos alunos o real objetivo da sequência didática no contexto da sala de aula, até o final da sequência para avaliar e informar os resultados. (OLIVEIRA, 2013, p. 40)

Vizolli; Oliveira (2020, p. 5), concebem Sequência Didática

como um conjunto de atividades organizadas, articuladas, ordenadas e encadeadas entre si, as quais comportam níveis de complexidades cada vez maiores, de modo a conduzir os sujeitos a compreenderem um determinado conceito. Assim, o professor e os estudantes são sujeitos ativos no processo de ensino e aprendizagem. Uma vez que os conceitos matemáticos conectam-se uns aos outros, há necessidade de estudos reflexões, a fim de planejar as atividades adequadamente.

Com o "objetivo de analisar as contribuições do PNAIC ao processo de ensino de matemática no Ciclo de Alfabetização, na Escola de Tempo Integral Padre Josimo Morais Tavares, em Palmas, TO” (PUGAS, 2018, p. 9), a autora desenvolveu seu estudo a partir de 
observações no espaço escolar e entrevistas realizadas com 05 (cinco) professoras alfabetizadoras, a coordenadora municipal do Pacto Nacional pela Alfabetização na Idade Certa e a supervisora escolar. Para tanto, sustentou teoricamente sua pesquisa, sobretudo em teóricos como Fonseca, Nacarato, Mengali e Passos. Os resultados da pesquisa de Pugas (2018)

\begin{abstract}
demonstram contribuições significativas do PNAIC para a prática docente, identificadas no desenvolvimento de saberes disciplinares e curriculares dos professores, bem como na compreensão de conceitos inerentes ao ensino da matemática no Ciclo de Alfabetização, assumidas nas práticas dos professores, tais como letramento matemático, o lúdico como estratégia para o ensino na infância e a resolução de problemas, e para a ampliação da compreensão da avaliação da aprendizagem visando o desenvolvimento da aprendizagem dos estudantes. (id ibid)
\end{abstract}

Tomazeli (2018, p. 8) tematiza o curso de formação continuada Projeto de Estudo e Intervenção Pedagógica (PEIP), desenvolvido pelo estado do Mato Grosso. Se dispõe a "analisar como os professores compreenderam, desenvolveram e avaliaram as ações que envolveram os conhecimentos matemáticos no PEIP”. Para isso desenvolveu sua pesquisa com 05 (cinco) professoras alfabetizadoras de Cáceres (MT), a partir de "entrevistas, caderno de campo, observações, cadernos dos alunos, cadernos de registros avaliativos, planejamentos".

Ancorada nos estudos Gatti, Barreto; Imbernóm; Fiorentini, Nacarato; D’Ambrósio; Chacón; Darsie; Palma; Moura; dentre outros, conclui sua dissertação asseverando que o curso não favoreceu o protagonismo docente; desconsiderou as necessidades formativas na perspectiva dos docentes; "representou mais uma tentativa de controlar o que é ensinado na escola" (id ibid).

Madureira (2019), apresenta uma análise do Programa de Formação Continuada de Professores Alfabetização Matemática, Leitura e Escrita (ALFAMAT), ofertado pela Secretaria Municipal de Educação e Cultura (SEMEC) de Belém, (PA), em relação as percepções de 07 (sete) professores que atuam no Ciclo II do Ensino Fundamental ( $4^{\circ}$ e $5^{\circ}$ Anos), na perspectiva de identificar os efeitos do curso sobre a prática docente. Para isso, lançou mão de consulta bibliográfica e documental, bem como da realização de entrevistas com os participantes da pesquisa.

Embora os professores indiquem aspectos favoráveis em relação ao curso, tecem "críticas e sugestões quanto ao modo como gostariam que fossem conduzidos os programas de Formação Continuada, por exemplo, este que foi desenvolvido pela SEMEC/Belém, o que indica a necessidade de privilegiar outros aspectos que não aqueles que decorrem das avaliações em larga escala" (MADUREIRA, 2019, p. 8). 
Siebert Silva (2015) e Barros (2018), se dedicaram ao processo de ensino e aprendizagem de fração por professores de $4^{\circ}$ e $5^{\circ}$ Anos do Ensino Fundamental, em relação ao conceito de fração. Enquanto Siebert Silva (2015), buscou identificar as dificuldades manifestadas por 03 (três) professoras de duas escolas de Cuiabá, (MT) apresentaram em um processo formativo, consubstanciando-se na Teoria Histórico-cultural (Vigotsky; Leontiev; Moura), Barros (2018), analisou o modo como 98 professores da rede pública municipal de Araguaína, (TO), resolvem situações de fração que envolvem, diferentes significados (Merlini; Silva), a utilização de diferentes registros de representação semiótica (Duval) e as características das quantidades (Nunes et al).

Interessante destacar que em ambos os estudos ficou evidente que os professores apresentam algumas dificuldades em relação a compreensão do conceito de fração, bem como em relação ao fazer pedagógico.

\footnotetext{
Os resultados indicam que as professoras tiveram poucas oportunidades de acesso e atribuição de significado para o estudo de frações em suas trajetórias, escolar, acadêmica e profissional. Dentre as aprendizagens manifestadas pelas professoras, apontamos quanto ao conhecimento específico, a atribuição de outros significados para as frações além de parte/todo e quociente (SEIBERT SILVA, 2015, p. 8).

Verificou-se, também, dificuldades em compreender e solucionar situações que envolvem fração quando se trata da conversão entre registros de representação semiótica e, principalmente dos significados número, medidas, quociente e operador multiplicativo (BARROS, 2018, p. 8).
}

Barros (2018) assevera que muitas vezes os participantes fazem uso de figuras geométricas como círculos, triângulos ou retângulos para resolver situações que envolvem fração, o que é importante, mas não suficiente para fins da compreensão desse conceito por parte dos cursitas. Tanto Siebert Silva (2015) como Barros (2018), destacam que os professores devem compreender o conceito de fração a fim de ensinar, de modo que favoreça com que os estudantes se apropriem desse conhecimento de forma a levá-los a resolver situações com as quais se deparam em seu dia a dia. Segundo Siebert Silva (id ibid), trata-se de um "processo de humanizar-se e fazer-se professor".

Historicamente a problemática do contexto socioambiental da Amazônia Legal Brasileira (ALB) tem sido objeto de noticiários nacionais e internacionais, o que criou no imaginário social, uma representação de que a Amazônia é formada por uma imensa floresta inundada pelas águas onde vivem, isoladamente, algumas etnias indígenas. Representação essa, que nem perto se aproxima da diversidade social, ambiental e cultural que constitui a ALB. Paradoxalmente, pouca visibilidade é dada à diversidade de contextos socioculturais e menos 
ainda se atenta aos processos educacionais desenvolvidos ou destinados às populações que vivem e constroem a história nesse imenso território.

O desenvolvimento de pesquisas que tematizem os processos educacionais deve considerar o engendramento dos saberes e fazeres produzidos pelas populações e que caracterizam a diversidade cultural da Amazônia Legal, cujo território alcança outros países que compõem a América Latina, com os saberes da docência, sobretudo de Matemática nos Anos iniciais do Ensino Fundamental. Ao se pensar na formação de professores, por exemplo, há que se considerar que, mesmo diante da dificuldade de acesso aos processos educacionais formais, as populações indígenas, do campo, das águas, das florestas, ribeirinhos, assentados, das cidades, particularmente nas zonas periféricas, das favelas, atingidos por barragens, seringueiros, dentre outras, são produtoras de conhecimentos, os quais são repassados às gerações subsequentes, especialmente por meio da oralidade, cuja aprendizagem ocorre a partir do exemplo e por iniciativa do sujeito, diferentemente do modo como acontece nas sociedades eurocêntricas.

A formação continuada tematizada pelos pesquisadores reverbera contribuições e fragilidades: do Pacto Nacional Pela Alfabetização na Idade Certa (PNAIC), desenvolvido em âmbito nacional; bem como de cursos ofertados pelas Secretarias de Educação, como é o caso do Projeto de Estudos e Intervenções Pedagógicas (PEIP), desenvolvido no estado do MT; o Programa de Formação Continuada de Professores Alfabetização Matemática, Leitura e Escrita (ALFAMAT) de Belém, PA; projetos desenvolvidos por grupos de estudos ou pesquisas, a exemplo do Projeto Observatório da Educação com foco em Matemática e Iniciação às Ciências (OBEDUC), da UFMT; e Aprendendo Matemática desenvolvido por professores e mestrandos da UFT. Ao mesmo tempo em que as pesquisas reconhecem as contribuições desses programas/projetos, especialmente em relação aos processos didático-metodológicos (COSTA 2015; SILVA 2015; CALLEJAS, 2017; PUGAS, 2018; TOMAZELI, 2018; MADUREIRA, 2019) e mesmo em relação a ampliação na compreensão de conceitos matemáticos como é o caso das frações (SIEBERT SILVA, 2015; BARROS 2018), denunciam a utilização de pacotes hermeticamente fechados para realizar formação continuada, o que, na maioria das vezes, não atende as demandas educacionais de professores e estudantes; a falta de um olhar mais crítico em relação a realidade vivida pelos alfabetizadores e demais professores que atuam, especialmente nos Anos Iniciais do Ensino Fundamental, em seus contextos escolares e aos saberes oriundos de suas práticas; a pouca atenção da formação inicial em relação aos conteúdos, ao ensino e a aprendizagem de conceitos matemáticos. Destaca-se ainda a 
necessidade de se desenvolver pesquisas a partir do Programa da Escola da Terra, o qual tem assento aos processos educacionais voltados aos trabalhadores rurais.

Em relação aos aspectos metodológicos é possível verificar que os estudos se enquadram no escopo das pesquisas qualitativas, nas quais os autores preocuparam-se em descrever pormenorizadamente as situações, de modo a alcançar a complexidade do fenômeno, o que muitas vezes requer a atuação direta dos pesquisadores na ação, especialmente quando se trata de captar ideias em relação as situações que envolvem variáveis a serem evidenciadas. A produção de dados para realização dos estudos aconteceu a partir de recursos como narrativas orais, escritas ou videografadas, cadernos de anotações, planejamentos, atividades realizadas pelos participantes das pesquisas, ou ainda entrevistas, o que exigiu encontros entre duas ou mais pessoas, a fïm de se obter informações acerca de determinado assunto/situação/fenômeno em estudo, cujos diálogos se desenvolvem a partir da natureza da pesquisa. Muitos diálogos foram realizados a partir de um roteiro semiestruturado contendo perguntas abertas elaboradas a partir das variáveis a serem consideradas no estudo.

O sobrevoo pela Amazônia, o andarilhar em suas águas e trilhas, assim como a caminhada em terra firme contribuiu na demarcação de um campo de pesquisa que carece de uma ausculta meticulosa a fim de propor alternativa que coloquem os professores e estudantes na centralidade do processo de formação continuada. Nesse sentido, se faz necessário (re)viver os voos, mergulhos e trilhas com um novo olhar.

\section{5. (Re)viver os voos, mergulhos e o andarilhar pelas trilhas amazônicas com novo olhar}

As pesquisas indicam que os cursos de formação continuada têm assento na metodologia de ensino, com foco em atividades lúdicas, a exemplo de jogos, como é o caso do PNAIC; o uso de Sequência Didática, a exemplo do PNAIC e do grupo de professor e estudantes do Mestrado em Educação da UFT, e ao uso de tecnologias, estas nem sempre acessíveis a professores e estudantes, especialmente na Amazônia Legal Brasileira.

A análise das produções acadêmicas desenvolvidas em Instituições de Ensino Superior localizadas na ALB que tematizam a formação continuada em Matemática para os Anos Iniciais do Ensino Fundamental, permitiu que identificássemos uma riqueza que carece de visibilidade, especialmente por parte do poder público e dos responsáveis pela formação inicial e continuada de professores. Os resultados desses estudos ressoam as bases de sustentação teórica que versam sobre formação continuada para professores, assentando-se nos estudos que enfocam saberes docentes (Tardif, Shulman, Ibernón, dentre outros) e desenvolvimento profissional, como é o 
caso de Garcia, Nóvoa, Freire, dentre outros. Estes Estudiosos alertam para a necessidade de se colocar o professor como agente e ator no processo de formação.

Os estudos indicam a falta de articulação dos cursos de formação continuada em relação aos saberes e fazeres característicos das comunidades em que as escolas estão inseridas, ou em outros termos, aos conhecimentos socioculturais produzidos pela existência humana. Ademais, é necessário que as instituições formadoras de professores se atentem para o fato de que professores e estudantes são protagonistas no fazer de sala de aula e, portanto, devem compor a centralidade do processo de ensino e aprendizagem. Isso significa, sobretudo, que os professores sejam formados na perspectiva de que possam refletir sobre suas práticas, de modo a tornarem-se protagonistas e pesquisadores em sua ação docente.

Estes estudos reverberam a necessidade de que o professor formador de professores se sensibilize para o diálogo e a ausculta aos saberes daqueles que historicamente foram invisibilizados e silenciados pelo sistema social e no próprio fazer de sala de aula dê voz e vez aos oprimidos, a fim de que eles possam falar de si para que outros saibam de suas existências, a partir de sua cultura. Ademais, os resultados das pesquisas reverberam a necessidade de políticas de formação continuada permanentemente, de modo a atender as demandas da formação humanizada, localizada e que contemple a riqueza sociocultural da Amazônia Legal Brasileira.

\section{Referências}

BARROS, Marcos José Pereira. A solução de situações que envolvem o conceito de fração por professores que ensinam Matemática nos anos iniciais. 2018. 229f (Mestrado em Educação) - Programa de Pós-Graduação em Educação - PPGE, Universidade Federal do Tocantins - UFT, Palmas, TO, 2018.

CALlEJAS, Ieda Maria Valle Monteiro. Pacto Nacional pela Alfabetização na Idade Certa (PNAIC): as vozes de professoras sobre a formação continuada e as práticas escolares em Matemática. 2017. 168 f (Mestrado em Educação) - Programa de PósGraduação em Educação - PPGE. Universidade Federal do Mato Grosso - UFMT. Cuiabá, MT, 2017.

COSTA, Lucélida de Fátima Maia da. Vivências autoformativas no ensino de Matemática: vida e formação em escolas ribeirinhas. 2015. 178 f (Doutorado em Educação em Ciências e Matemática) - Instituto de Educação Matemática e Científica - IEMCI. Programa de PósGraduação em Educação em Ciências e Matemáticas - PPGECM. Universidade Federal do Pará - UFPA. Belém, PA, 2015.

FERREIRA, Norma Sandra de Almeida. As pesquisas denominadas "estado da arte". In: Educação \& Sociedade [online]. 2002, v. 23, n. 79, pp. 257-272. Disponível em 
<http://www.scielo.br/scielo.php?pid=s0101-

$73302002000300013 \&$ script=sci_abstract\&tlng=pt $>$ Acesso em 18/03/2020

Gil, Antônio Carlos. Como elaborar projetos de pesquisa. 4. ed. São Paulo: Atlas, 2002

GODOY, Arilda Schmidt. Pesquisa qualitativa: tipos fundamentais. In: Revista de Administração de Empresas. São Paulo, v. 35, n. 3, pp. 20-29 Mai./Jun. 1995

MADUREIRA, Nila Luciana Vilhena. O programa ALFAMAT na prática pedagógica de professores: um estudo em escolas municipais vinculadas à SEMEC - Belém. 2019. $233 \mathrm{f}$. (Mestrado em Educação). 2015. 178 f (Doutorado em Educação em Ciências e Matemática) Instituto de Ciências da Educação - ICED. Programa de Pós-Graduação em Educação PPGED. Universidade Federal do Pará - UFPA. Belém, PA, 2019.

MARCONI, Marina de Andrade; LAKATOS, Eva Maria. Fundamentos de metodologia científica. 5. ed. São Paulo: Atlas, 2003.

MOROSINI, Marilia Costa. Estado de conhecimento e questões do campo científico. In: Revista do Centro de Educação UFSM. Santa Maria, v. 40, n. 1, p. 101-116, jan./abr. 2015.

PUGAS, Seila Alves. Entre números e letras considerações de professoras alfabetizadoras da escola de tempo integral Padre Josimo Morais Tavares (Palmas-TO), sobre as contribuições do PNAIC para suas práticas de ensino de Matemática. 2018. 203 f. (Mestrado em Educação) - Programa de Pós-Graduação em Educação - PPGE, Universidade Federal do Tocantins - UFT, Palmas, TO, 2018.

SANTOS, Antônio Raimundo dos. Metodologia científica: a construção do conhecimento. $7^{\text {a }}$. ed. Rio de Janeiro - RJ: Lamparina, 2007

SILVA, Fabio Colins da. Saberes docentes na/da formação continuada de professores que ensinam Matemática no ciclo de alfabetização. 2015. 175 f. (Mestrado em Educação em Ciências e Matemática) - Instituto de Educação Matemática e Científica - IEMCI. Programa de Pós-Graduação em Educação em Ciências e Matemáticas - PPGECM. Universidade Federal do Pará - UFPA. Belém, PA, 2015.

SIEBERT SILVA, Vani Terezinha. Estudo e ensino de frações: aprendizagens e dificuldades docentes no processo de formação continuada. 2015. 188 f (Mestrado em Educação) - Instituto de Educação. Programa de Pós-Graduação em Educação - PPGE. Universidade Federal do Mato Grosso - UFMT. Cuiabá, MT, 2015.

OLIVEIRA, Maria Marly de. Sequência Didática Interativa no processo de formação de professores. Petrópolis, RJ: Vozes, 2013.

TOMAZELI, Lenir. Formação continuada de professores que ensinam Matemática no primeiro ciclo: análise do projeto de estudos e intervenções pedagógicas em uma escola pública de Cáceres, MT. 2018. 149 f (Mestrado em Educação) - Instituto de Educação. Programa de Pós-Graduação em Educação - PPGE. Universidade Federal do Mato Grosso UFMT. Cuiabá, MT, 2018. 
ZABALA, Antoni. A prática educativa: como ensinar. Trad. Ernani F. da F. Rosa. Porto Alegre: Artmed, 1998.

VIZOLLI, Idemar; OLIVEIRA, Ritianne de Fátima Silva de. Narrativas de professores sobre Sequência Didática: contribuições de uma formação continuada sobre fração. In: Revista de Matemática, Ensino e Cultura (REMATEC) v 34, 2020 (no prelo).

VIZOLLI, Idemar; PUGAS, Seila Alves. Narrativas de alfabetizadoras sobre contribuições da formação do PNAIC ao processo de ensino e aprendizagem de Matemática em uma escola pública municipal de Palmas, Tocantins. In: Revista da Rede Amazônica de Educação em Ciências e Matemática (REAMEC). Cuiabá (MT), v 8, n 2, pp 167-84, maio-agosto 2020.

Submetido em: 28 de agosto de 2020 .

Aprovado em: 25 de outubro de 2020. 